\title{
Sharing initial teacher education between school and university: participants' perceptions of their roles and learning
}

\author{
Teresa Mauri, Javier Onrubia, Rosa Colomina \& Marc Clarà
}

To cite this article: Teresa Mauri, Javier Onrubia, Rosa Colomina \& Marc Clarà (2019): Sharing initial teacher education between school and university: participants' perceptions of their roles and learning, Teachers and Teaching, DOI: 10.1080/13540602.2019.1601076

To link to this article: https://doi.org/10.1080/13540602.2019.1601076

Published online: 04 Apr 2019.

Submit your article to this journal $\square$

Џ Article views: 21

View Crossmark data $\complement$ 


\title{
Sharing initial teacher education between school and university: participants' perceptions of their roles and learning
}

\author{
Teresa Mauria , Javier Onrubia ${ }^{a}$, Rosa Colomina ${ }^{a}$ and Marc Claràb \\ a Department of Educational and Developmental Psychology, University of Barcelona Campus Mundet \\ Universitat de Barcelona, Barcelona, Spain; ${ }^{b}$ Department of Pedagogy and Psychology, University of Lleida, \\ Lleida, Spain
}

\begin{abstract}
This paper considers how student teachers, mentor teachers and university tutors who participate in collaborative settings for joint reflection on practical teaching situations during students' practicum perceive their roles and opportunities for learning in these settings. We are also interested in how the participants experience this kind of collaboration between schools and university in the context of initial teacher education. To this end, we created and analysed three settings for joint reflection among mentor teachers, university tutors and students. Twenty-seven students teachers in three schools as part of their Primary Education degree took part, along with their respective mentor teachers and university tutors. All the discussion sessions were videotaped and the participants were interviewed in-depth about their experience. Content analysis of the resulting material enabled us to describe the dynamics of interaction in each setting, the perceived role of mentor teachers and university tutors, and the participants' perceptions regarding the learning achieved. We conclude that, for the participants, the creation of these settings for joint reflection enabled mutual learning and closer collaboration between schools and university, bringing greater coherence to practicum.
\end{abstract}

\section{ARTICLE HISTORY}

Received 27 July 2017

Accepted 22 March 2019

\section{KEYWORDS}

Practicum; school-university collaboration; mentors roles; expansive communities of practice; joint reflection settings

\section{Introduction}

Practicum is a period of initial teacher training that gives the students opportunities of practical experience of teaching at school. Although different countries have designed different teacher practice systems, practicum is universally considered as one of the core components of any teacher-training program.

Practicum has been widely studied in recent years (Ch. \& He, 2010). Research has been interested in the opportunities that practicum offers for learning to teach from personal experience in real contexts, actively involving students in communities of practice, and working cooperatively with teacher educators that guide student teachers reflection and processes of decision-taking. From their analysis of literature, Ch. and $\mathrm{He}$ (2010) propose two general conclusions: "(i) the support from the practicum school and the role of mentor teachers are perceived crucially important. (...) (ii) Collaboration 
between schools and universities is underscored' (p. 60). Both conclusions coincide with the turn given by different countries to teacher training. This turn questions the central role of the university in such training (Darling-Hammond \& Lieberman, 2012; Grossman \& Loeb, 2008) and promotes a change of emphasis in the place where training is offered, postulating that schools, and not only universities, are a key learning place (Maandag, Deinum, Hofman, \& Buitink, 2007).

\section{School-university partnerships}

In order to contribute to make initial teaching training much more practice-focused, it has been proposed that universities have to modify their relationship with schools, developing a kind of association based on mutual engagement and responsibility for student teachers training-partnerships. Partnerships are conceptualised in different ways in different countries, so bringing to different models of partnership (Furlong, Barton, Miles, Whiting, \& Whitty, 2000; Lynch \& Smith, 2012; Moran, Abbott, \& Clarke, 2009): (i) hierarchical, in which the nature and scope of the experience is controlled by the university; and (ii) collaborative-which is considered as the most desirable (Smith, Brisard, \& Menter, 2006; Zeichner, 2010). The idea behind the potential improvement that collaborative partnership offers is the belief that learning to teach should be a joint venture between schools and universities, and that student teachers require appropriate academic, practical and personal support in order to smoothly navigate the different settings for teacher education' (Mtika, Robson, \& Fitzpatrick, 2014, p. 67).

However, different problems arise in order to build collaborative, authentic partnerships between school and teacher universities (Anagnostopoulos, Smith, \& Basmadjian, 2007; Cope \& Stephen, 2001; Smith et al., 2006). One of the main problems is the existing disconnection between universities and schools. This disconnection has been related with: (i) dividing training between different spaces-the university and the school (Cuenca, Schmeichel, Butler, Dinkelman, \& Nichols, 2011); (ii) different kinds of knowledge in both institutions-academic knowledge and practical knowledge (Cochran-Smith \& Lytle, 2009); and (iii) student teachers' perception of a lack of communication between university and school, resulting in a lack of practicum's coherence.

As a consequence, universities are being challenged to re-think how they interact with schools in teacher training programs, in order to optimise the learning experience that both of them can provide to the student teachers. Studies on partnership between schools and universities point that a key factor for attaining this aim is to develop projects that are able to align the needs and satisfy the expectations of all the involved parts (Lynch \& Smith, 2012).

Considering those issues, some authors suggest that partnerships should be reconceptualised (Moran et al., 2009; Mtika et al., 2014). Building on the ideas and conceptualisations of Vygotsky and Human Activity Theory about human activity as collective, culturally mediated activity, they suggest that school teachers and university educators should work together in order to attain a 'co-constructive perspective that can facilitate cross-institutional communication and collaboration' (Anagnostopoulos et al., 2007, p. 140). They also build on the contributions by Zeichner (2010) about 'hybrid spaces': a communicative and relational space that links teachers and teacher educators involving 
them in the development of shared relationships in a framework of a non-hierarchical, authentic association. In this framework, each institution recognises and values the knowledge that the other institution brings to the joint situation, and the relationship between both institutions aligns in a 'more synergic' way (Zeichner, 2010, p. 93).

This hybrid space has also been named as a 'third space' (Gutierrez, Rymes, \& Larson, 1995). On the one hand, this third space aims at fostering a non-hierarchical communicative relationship, recognizing that communication is not typified by the predominant traditional discourses, which seek to silence competing narratives and different voices (Levine, 2010), but rather by a position that recognizes and integrates the manifestation of all existing ones. On the other hand, this third space aims to put an end to the tensions due to the dependence on training and its location in different cultural environments (school and university). This kind of space provide an opportunity for the development of new communities of practice, communities that differ but are related to the communities of departure of the different members in this third space. So, a new conceptual framework can develop, that can only be achieved through acceptation and legitimation of a new developing culture, which is neither the culture of the school nor the culture of the university.

For Gorodetsky and Barak (2008), this proposal can be interpreted from the 'ecological edge metaphor', in which: 'the transitional zones influence their cultures of origin by increasing diversity and flexibility. (...) [This metaphor] seems to be promising in understanding processes of change and growth in collaborative systems' (p.1908). In this conceptual framework, the need of creating an 'expansive community of practice' (Mtika et al., 2014) is highlighted: [a community that is characterised by] 'deliberated two and three way professional exchange within the shared framework; informed interconnections across school-university 'boundaries'; more active roles and defined responsibilities for all participants; collective learning and professional dispositions, and collaborative development and enactment of activities' (p. 68). From the ecological edge metaphor, this expansive community is conceptualised as peripheral to both original communities (school and university), and it has 'new, culturally distinguished features (...) [that can serve] as a context that eventually leads the core communities in new directions' (Gorodetsky \& Barak, 2008, p. 1909).

\section{Mentors' roles and responsibilities}

Literature review highlights that the role of mentors is a complex function (Crasborn, Hennissen, Brouwer, Korthagen, \& Bergen, 2010, 2011; Hennissen, Crasborn, Brouwer, Korthagen, \& Bergen, 2008, 2011; Hoffman et al., 2015; Korhonen, Heikkinen, Kiviniemi, \& Tynjälä, 2017; Mena, García, Clarke, \& Barkatsas, 2016; Mena, Hennisen, \& Loughran, 2017). In spite of the relevance given to mentoring in teacher training, a unified terminology about mentoring has not been developed. Moreover, a clear, shared meaning of the term has not been attained within the academic and professional discourse. Additionally, most of mentoring literature has focused on the role of mentor teachers at the school level, but the role of the university tutor, or the joint action of mentor teachers and university tutors with the student teachers, have been far less studied. 
In recent years, a view of mentoring in which relationship between the participants is recognised as a fundamentally dynamic and reciprocal collaboration has emerged (Geerarerts et al., 2015; Heikkinen, Jokinen, \& Tynjälä, 2012; Korhonen et al., 2017). For instance, in Finland, mentoring practices have been developed according to the Peer Group Mentoring model (PGM), in which the participants become "genuinely involved in one another's learning as well as their own, and are positioned 'as colearners as they engage in professional dialogue with other' (Le Cornu, 20,015, p. 358).

One way to identify the adoption of certain mentor roles to support student teachers in practice is the MERID model (Hennissen et al., 2008, 2011; Hoffman et al., 2015; Mena et al., 2017). The MERID model (Mentor- teachers- Roles In Dialogues) consists of two independent dimensions: (i) Directivity, which indicates the degree to which the mentor directs the course of the dialogue (Non-directive; Directive); and (ii) Input, which indicates the degree to which the mentor enters topics in the dialogue (Active; Reactive). Following the authors, the combination of these two dimensions results in four different roles of mentor teacher, ranging from the most directive to the least directive: Initiator, Imperator, Advisor and Promoter (Crasborn et al., 2011).

Directive mentors usually focus on giving evaluative-retroactive feedback in a direct manner (advice, explicit and concrete suggestions-what the student should have done differently, what he/she should do, what to do to improve their teaching). At the same time, their use of questions aimed to elicit the development of the student teacher thinking about his practice is scarce, and their action is focused on showing the students the right ways of teaching.

Non-directive mentors offer to the student teachers opportunities to reflect on their own action, and use a conversational-reflective style when dialoguing with the students, creating opportunities for the students to lead the conversation. They tend to raise questions, guide the student to develop alternatives, react empathetically, summarise their contributions to conversation, and listen actively. They also bring the students to ask themselves general questions and to discuss their educational needs or concerns (Harrison, Lawson, \& Wortley, 2005). Non-directive mentors also encourage the student teachers to keep reflecting on the situations, to elaborating their own knowledge and build their own voice; they also reflect on the forms of participating and attaining educational aims.

Considering the focus of the interaction, Crasborn et al. (2011) shows that mentors usually focus their conversation with student teachers or pre-service teachers more on planning or instructional actions than on reflective conversations behind their actions or the students in the classrooms. So mentor teachers 'shared her methods for considering the content, the resources, and the students in lesson planning and rarely asked questions calling for justification of purpose on part by the student teacher' (Hoffman et al., 2015, p. 106). It is possible that mentors act this way because they are more worried about their classroom children's learning than about the student teachers' learning (Edwards \& Protheroe, 2004).

Mentors who direct conversation also tend to help the student teachers to describe their practice in a narrative way, whereas non-directive mentors tend to promote a more abstract, general view of practice and a more inferential, deductive professional knowledge. This more inferential approach can lead student teachers to a better learning from their practical experience, because inferential knowledge allows them "to 
perceive analogies better, operate with concepts in practice, and refer to high-order ideas rather than just referring to events" (Mena et al., 2017, p. 57).

Anyway, it is important that mentors reflect on which kind of learning they want to promote in their interaction with student teachers and on the level of complexity or abstraction they want for this interaction, so using the strategies that are most suited to their aims. In this sense, different authors (Crasborn et al., 2010; Erbilgin, 2014; Hennissen et al., 2011) have shown that, with an appropriate training, both directiveness and focus of interaction between mentor teachers and student teachers can change. In particular, they can evolve from an evaluative feedback towards asking preservice teachers open-ended questions that prompted reflection, and from an advisor/instructor role to an encourager role. However, this kind of progress is not automatic. So, it is important to keep studying how the mentor role can be concreted in different spaces and within a framework of formative mentoring.

\section{Research questions}

In accordance with the idea that practicum should contribute to create a new community which at the same time interacts with and influences the original communities of the school and the university, we designed and developed for our study three settings or 'spaces' for shared reflection on teaching practice during the practicum, established in a coordinated way. Each one of these spaces was designed to contribute in a specific manner for student teachers to relate theory and practice. In the School Setting, a reflection space shared by the mentor teacher and his/her student teacher, it was intended that student teachers gain access to how mentor teachers interpret the situations under reflection and how they use their conceptual knowledge in context, dealing with the particular restrictions that frame the considered situations. The University Setting was designed as a reflection space where a university tutor met with a group of student teachers. It was aimed to assist the student teachers to use their academic knowledge in order to inform their analysis and understanding of the practical situations, so using this knowledge in a dialectical, non-mechanical manner-as an element that contributes to the 'reflective conversation' with the coped situation. Finally, the Joint Setting, a space in which mentor teachers, university tutors and student teachers reflect together at the school, was intended to relate, in a collaborative, non-hierarchical manner, the diverse understandings of the situation by the different participants, in order to achieve a better mutual understanding and a richer shared comprehension.

From this design, it is worth mentioning that our study approaches mentoring in a broad sense, including both school mentor teachers and university tutors supporting student teachers. Moreover, mentoring also refers in our study to processes of comentoring (Mullen, 2000) and peer mentoring (Le Cornu, 2005) that can appear in the Joint Setting. In this Setting, school mentor teachers and university tutors can grew professionally as reflective teachers and mentors because of their collaboration and joint commitment to help their student teachers similarly to learn to teach through reflection. Sharing and discussing experience of mentoring in partnership can influence their practices of teaching and mentoring. Therefore, this Setting can contribute not only to student teachers' development, but to the mentor's development as well. 
Within this context, our research questions were as follows: (a) How do the participants perceive their role in the different settings? (b) To what extent is participation in the different settings seen as a learning opportunity? (c) Do the participants regard the settings as a useful way of linking school and university? We will analyse each of these aspects for each of the developed settings.

\section{Method}

The study adopts an interpretive approach that focuses on the participants' experience and seeks to understand how they carry out and interpret their respective training tasks under the new conditions (Van Manen, 2003).

\section{Participants}

The study was conducted at the University of Barcelona in the context of the practicum that forms part of the Primary Education Degree. The practicum involves three courses distributed across the degree as a whole: Practicum I (PI, year two; one month duration); Practicum II (PII, year three; three months duration); and Practicum III (PIII, year four; one month duration). For each of these courses a group of approximately 15 students is assigned to an university tutor (UT), and each student teacher (ST) has a mentor teacher (MT) in the school where the ST is on placement.

For the purposes of the study the usual tutorials with the UT and those with the MT were reframed in accordance with the criteria set out in the previous section. They thus became the University Setting and the School Setting, respectively. Additionally, we created the Joint Setting in which students on placement at the same school came together with their respective university tutors and mentor teachers.

In order to be able to create the three settings we agreed with three schools that they would (1) take at least three ST for each of the three practicum courses (nine students) and (2) establish the proposed settings for each of these courses. Each UT who participated in the study (1 in PI, 2 in PII and 1 in PIII) had at least three students in each of the schools, and these students took part in each of the three types of setting.

The three schools volunteered for participation in the study. Their socioeconomic context, pedagogical options, and teaching staff were diverse, but all of them were parallel to the kind of schools in which student teachers usually develop their practicum in our context. All the schools were experienced in dealing with student teachers. The teachers tutoring the students also volunteered for participation in the study. They were teaching at different levels of the primary school, and, for the most of them, they were experienced in tutoring student teachers during their practicum. The STs who participated in the study were the ones that choose to develop their practicum in the schools participating in the study. Besides this, the students who participated in the study were similar to their grade fellows. Finally, the UTs who participated in the study had wide experience in tutoring student teachers during their practicum.

Overall, and in each school, we conducted 19 sessions of the University Setting ( 3 in PI, 10 in PII and 6 in PIII); 57 sessions of the School Setting ( $3 \times 3$ students in PI, $11 \times 3$ students in PII and $5 \times 3$ students in PIII); and 10 sessions of the Joint Setting ( 2 in PI, 5 in PII and 3 in PIII). 


\section{Procedure}

In-depth interviews were held with the MTs, UTs and STs who took part in the three types of setting during the three practicum courses, and a focus group was held with the management team of each school in order to complement the information obtained. Each interview lasted approximately 60 minutes and followed a semi-structured format. The interviews began with a general introduction to the experience of the practicum. Then, each of the participants was asked about the settings in which he or she had taken part, focusing specifically on aspects related to our research questions: organization and functioning of the reflection setting; role of the participants in each setting; perceptions regarding learning; the link between school and university; and sustainability of the proposal.

All the interviews were audio-recorded, ensuring the participants' confidentiality at all times. The sessions held as part of each of the three settings were video-recorded so that they could be viewed subsequently in the event that the individual interviews yielded considerably discrepant opinions among participants as to the content of the setting sessions. All participants were informed about the purpose and characteristics of the research, and they signed informed consent regarding their involvement. During the six months of the study, data were collected in each school and at the university by a team of four researchers. The information obtained in the interviews was complemented with that gathered in the focus group, and, when necessary, it was compared with the video recordings.

All the interviews were transcribed and the resulting material was analysed using a procedure of thematic analysis (Braun \& Clarke, 2006). Specifically, through an iterative process involving the constant comparison of data and emergent categories, the research team identified patterns and themes in the statements made by participants, searching for both divergent and convergent aspects in them. These themes were then linked to a series of conceptual dimensions and sub-dimensions that had been established a priori based on the research aims and questions. The relationship between categories and data was revised iteratively until a consistent and exhaustive set of categories was obtained. Once the initial analysis was complete, two researchers then reviewed the results independently in order to confirm that the categories had been applied correctly and to ensure the reliability of the analysis, which in all cases was above $90 \%$.

\section{Results}

\section{School setting: perceptions regarding the role of the mentor teacher and of the learning achieved}

The MTs in each of the three practicum courses showed a clear commitment to the idea behind the School setting and established a weekly 30-minute discussion session, with a regular time and place being agreed in advance.

The MTs considered that their role in this setting was to encourage STs to engage actively with the conversation and to help them reflect on the teaching situations they brought for discussion. They believed that they encouraged students' participation through their willingness to answer the students' questions, to give them the information they needed and to resolve their queries. Some MTs said that a key part of their role was to allow students to talk about the situation, offering them support so as to 
boost their confidence in their ability to interpret it, and asking them for their opinion. As regards helping students to reflect on the teaching situations, the teachers sought to provide them with information that would allow them to contextualise the situation. They also shared with STs their own experience in similar situations, as well as their own interpretation of the situation. When the situation under discussion had involved the ST observing the MT, the latter sought to explain the criteria on which her approach had been based and the reasons why she did the things she did. The aim here was to help the ST appreciate the complexity of classroom situations and to consider the need for flexibility in one's approach. With respect to the relationship between theory and practice, all the MTs said that they were much more interested in helping students understand the 'reality of classroom practice' than in showing them how they should act under 'ideal' conditions. The goal here was to temper some of the expectations regarding the practice of teaching that students often held as a result of the academic knowledge they acquired at university, expectations which the mentor teachers regarded as overly optimistic.

As regards the STs themselves, their views of the mentor teacher's role centred on two aspects: encouraging them to participate and helping them to reflect on their placement experience. With regard to the former, they said that mentor teachers allowed them to ask open-ended questions and encouraged them to avoid making judgements about the situation before they had reached a fuller understanding of it. They also considered that the MTs were willing to engage in active listening. With respect to reflection, the majority of STs said that the mentor teachers gave them information about the classroom context and the children involved, and encouraged them to offer their own interpretation. Another aspect of the teachers' role was to explain the criteria behind their approach to teaching and to give examples that better illustrated them. The students stated that the MTs shared their experiences with them and prompted them to ask questions, as well as suggesting alternative ways of doing things based on their interpretation of the situation. It can be seen, therefore, that the students and their MTs had similar opinions regarding the key aspects of the latter's role. In contrast to the MTs, however, the students made little mention of how the teachers contributed to the relationship between academic and practical knowledge, although they did emphasise how teachers introduced them to the realities of classroom practice.

In terms of perceived learning, the MTs said that one of the things they had learnt was that STs could not understand the practice of teaching merely through observation. When asked what, in their opinion, the students had learnt, the MTs noted the ability to talk with teachers and to identify with the various participants in the situation under discussion. They also believed that STs had learnt how to use the reflection sessions to improve their understanding of the situation, especially in terms of asking for information about the context and the characteristics of the children involved. Students had also become better, they believed, at identifying key factors related to each situation, as well as some of the criteria that accounted for the approach taken by the teacher. In this respect, they said that students had learnt the importance of basing one's approach to teaching on clear criteria, as well as certain strategies and resources for dealing with a given situation. With respect to the relationship between theory and practice, the MTs considered that students had learnt to appreciate the realities of classroom practice, beyond the view of teaching 
they had acquired at university, and were better able to identify the knowledge that teachers require. The STs themselves also mentioned all these aspects of learning. They also referred in addition to their improved ability to analyse and examine critically their placement experiences. The STs also considered that they had acquired new knowledge or skills in relation to specific issues and that this made them feel more confident about their own practice.

\section{University setting: perceptions regarding the role of the university tutor and of the learning achieved}

For the University Setting, the UTs involved in the three practicum courses created a weekly 90-minute discussion session, with a regular time and place being agreed in advance.

The tutors saw their own role as being to encourage STs to participate actively in the sessions, to promote reflection and to link theory and practice. With respect to participation, the UTs focused on building a relationship of trust and a space for joint reflection. Thus, they sought to create a communicational context characterised by mutual empathy and active listening in which all those involved felt comfortable and confident enough to share their personal opinions and particular experiences from their teaching placements. In terms of reflection, the UTs focused on helping STs to analyse and understand each classroom situation, rather than simply making judgements or suggesting solutions to problems. They also made room for a diversity of opinions and offered their own ideas as a way of furthering understanding of the situation. As regards the relationship between theory and practice, the UTs encouraged students to view their experiences in light of the knowledge they had acquired in all their university courses, not merely the practicum.

As for the STs themselves, they agreed that their UTs had aimed to create a climate of genuinely shared conversation, and that they had focused on understanding rather than evaluating or judging the teaching situations. They also considered that the UTs had helped them to analyse the situations in greater depth ('going further', 'seeing things we hadn't seen') and to identify key aspects on which to focus the reflection. According to the STs, the UTs achieved this in several ways: asking open-ended questions; answering the questions that students posed and resolving any queries; offering their own ideas, points of view and teaching strategies; guiding the analysis of the classroom situation; and focusing the discussion on points of conflict or dilemmas. The UTs also summarised the various contributions to the conversation, and this helped students to explicitly appreciate the value of joint reflection. With respect to the relationship between theory and practice, the tutors' role consisted in encouraging the application of theoretical knowledge, linking students' experiences to what they had learned at university, and offering an expert point of view. In summary, the students' view of their tutor's role coincided with the views of tutors themselves.

With regard to what had been learnt, the UTs considered that the process of joint reflection was not always easy for them to manage, and it was sometimes difficult to focus the analysis and discussion. Consequently, they learned that STs found it difficult: (1) to focus their participation on the goal of understanding; (2) to reflect on the teaching situation as a whole, and on the dilemmas it raised; and (3) to link theory and 
practice, recognising what they already knew and could use to explain and/or interpret the practical situation.

In terms of what the STs had learnt through the setting, the UTs said that they had improved their ability to think with others and to realise that this could boost their own learning. As regards the capacity for reflection, the UTs felt that, in general, their students had learned to go beyond first impressions and to analyse situations in greater depth, which they consequently considered in a more complex and relevant way. However, the UTs also said that students struggled to consider the dilemmas posed by the teaching situations, especially during the shorter placements. With respect to theory and practice, the UTs stated that students did not find it easy to identify what they already knew and could apply in order to understand the classroom situations, and in their view, they needed help to link theory and practice.

The STs corroborated their UTs' views in that they had learnt to take different points of view into account and to show empathy with others. As regards their ability to reflect, they agreed that understanding the classroom situations required thinking before offering an opinion, not simply sticking with the first idea that one has, and also that it was important to consider the situation as a whole. Another thing the STs said they had learnt was that more than one solution as possible. They also felt they had become better at identifying key aspects, including some of the complexities, of the classroom situations. The opportunity to analyse the situations together with their peers and UTs had enabled them to acquire new ideas and strategies for their future practice, and also to improve their existing skills. Hearing about their peers' experiences in different schools and classrooms was another aspect they identified as useful.

\section{Joint setting: perceptions regarding the roles of the mentor teacher and the university tutor, and of the learning achieved}

For the Joint setting the MTs, the UTs and the STs from each school (for each of the three practicum courses) took part in a periodic 90-minute discussion session, with the time and place being agreed in advance.

Here the MTs saw their role as being to take an active part in the joint discussion, helping to create a climate of trust that would enable all participants, especially the students, to offer their interpretations of the practical situations and to take on board the contributions of others. With regard to the reflective process, they saw their role as being similar to that in the School setting, namely to share their experience and to explain the basis for their approach to teaching, providing whatever information might be required about the classroom situation under discussion. The UTs and students agreed with the statements made by the MTs in this regard. In contrast to what occurred in the School setting, however, there were some differences in how the MTs from different schools saw their role.

As for the UTs, they considered that their role in this setting was to encourage everyone to participate in a climate of mutual respect, thus enabling a range of views to be expressed regarding the classroom situation under discussion. A particular goal for the UTs was that students were actively engaged with the discussion. In addition, they sought to emphasise their equal standing with respect to the MTs, such that students 
would regard the two agents as being jointly responsible for their training. Related to this was the idea that they should promote more in-depth reflection in conjunction with others (e.g. not acting as if they had ultimate responsibility for students' training, imposing their view of things or always having the last word). In order to support the participation of all those involved, the tutors avoided being openly critical of contributions made by the MTs that were contrary to their own views, and they aimed to base their own interpretations on solid and shared arguments. In terms of promoting reflection, the UTs guided the conversation whenever necessary, preventing the students from getting bogged down in issues that were unrelated to the objectives of the practicum. They also worked to ensure that the contributions of all those involved were explicitly acknowledged, emphasising the similarities in the various approaches to the situation and the issues under discussion.

The STs agreed with the statements made by the UTs, adding that the tutors also helped to resolve points of tension and were supportive. In terms of encouraging reflection, the students said that the UTs would look for similarities in the interpretations offered by others, expressing agreement and/or offering alternative or complementary perspectives, as appropriate. They also resolved queries and ended the session by summarising all the contributions made (i.e. both convergent and discrepant views). With respect to theory and practice, the STs said that the UTs presented their arguments in a way that illustrated the role of theory in understanding the practical situations under discussion. The MTs agreed with the students that the UTs had worked to encourage the participation of all those involved. They likewise agreed that the UTs had sought to promote reflection and show the importance of the theorypractice relationship, although they also felt that the tutors were often not very practical in their approach.

In terms of perceived learning, the STs said that their participation in the Joint setting had taught them 'how to be a teacher' and 'to develop a more personal understanding of education'. Several students stated that of the three settings, the Joint one had been the most fruitful and/or productive, and some of them considered that it had enabled them to confirm that they really wanted to enter the profession. The students also believed that they now had greater knowledge about how to approach practical teaching situations, and were better able to reflect. With regard to the latter, they said that they had learnt the importance of thinking before acting, and had a clearer idea about what the process of reflection involved. A further conclusion they reached concerned the need to adopt a broader systemic view when reflecting on teaching practice. Hearing about the experiences of their MTs was something they found useful in that it helped them to appreciate different approaches to teaching, to see how resources could be used and to begin linking their experience on placement with their academic knowledge (e.g. seeing practical examples of what they had been taught at university). They also said that they had come to realise that 'theory cannot always be applied in practice, and nor is there a seamless translation to the classroom setting'. Some STs said that they now understood better the demands involved in being part of a team of teachers. For example, teachers do not always agree with one another, and their different views need to be managed. In this context, they said they had learnt how it was possible to disagree and still work in harmony with one's colleagues. 
The UTs and MTs corroborated the views of students. When asked what they thought the students had learned, they said 'what it means to be a teacher'. They also considered that participation in the setting had helped the students to recognise key problems and needs in their respective classrooms and that they had learned how to reflect ('as an inherent part of classroom work') and to identify different ways of doing things in the situations analysed. With regard to participation, both sets of tutors emphasised that students had improved in this respect: the UTs noted that students contributed progressively more to the joint discussion, while the MTs said that students had learnt to value the contributions of others and to appreciate what it means to speak honestly about potentially delicate aspects of teaching practice. Finally, the MTs also stated that students had become aware of the range of views and approaches which may exist within a team of teachers, and that they recognised how teamwork is both crucial and difficult. With respect to the use of theoretical and practical knowledge, the tutors said that the students saw how a joined-up approach was often lacking.

As regards what the professionals themselves had learnt during the Joint setting, the MTs considered that they had learned to identify strong and weak points in their classroom practice and to share their interpretation of practical situations with other teachers. They also believed that they had learnt to reflect more deeply and to analyse whether they were really helping their students to do the same. As for the UTs, they considered that neither the process of the practicum nor the task of reflecting jointly with the mentor teachers had been straightforward. However, they said that participation in the setting had given them the opportunity to explore better ways of doing things and to identify new resources. They also felt that they had improved the help given to students in terms of understanding their placement experiences. With respect to the MTs, the UTs considered that they now had a better understanding of their role in training students, a role which they saw went beyond simply allowing students into their classrooms and required active intervention based on educational criteria that were shared by the university. They added that they were more aware of how difficult it could be for tutors to work together in meeting the training needs of students. In summary, all those involved in the Joint setting considered that the experience had enabled them to learn about key aspects of collaborative work.

\section{Discussion}

From the aforementioned results, it seems that the MTs and UTs in our study saw themselves as having mainly an 'Encourager' role (MERID model, Hennissen et al., 2008). They were oriented to promote participation and communication among the participants in the different Settings, make use of non-directives strategies (as a part of a broader range of strategies), and take students' reflections as a core focus of the interaction. Moreover, they were confident on the student teachers' abilities to interpret practical situations, and helped them to generate reflective abilities to communicate and discuss their own concerns (Harrison et al., 2005).

From this general role, both MTs and UTs combined different strategies in order to develop their students' knowledge. On the one hand, MTs maintained an open communication with the student teachers, based on open questions and active listening. Within this communication, they usually answered questions about the practical 
principles underlying their actions ('rules', Mena et al., 2016) and shared methodological strategies, resources and professional skills that they were using in the practical situations that are the object of reflection ('artefacts', Mena et al., 2016). On the other hand, they used in their conversations some kind of inferential knowledge. So, MTs in our study seemed to combine forms of intervention aimed to offer resources and a model of action-typical of a more directive role-with forms of intervention aimed to involve the students in the process of reflection, asking them to propose alternative forms of action different from the actions actually used in the situations, and positively valuing their critical reflective abilities-typical of a non-directive role.

In a similar vein, UTs promoted, on the one hand, students' participation in the joint reflection, by asking open questions and letting the students speak freely without trying to directly influence or change students' ideas. On the other hand, UTs actively contributed in order to present a more complex, dynamic and dilemmatic representation of the situation under reflection. This kind of contribution-typical of a directive role-aimed for students to evolve from direct descriptions of practice in terms of events or incidents ("recalls", Mena et al., 2016) and evaluations of the teachers' actions ('appraisals', Mena et al., 2016) to a more abstract and complex knowledge, which could use theoretical concepts and principles and focus on the identification of dilemmas in the situation.

Another interesting issue in both MTs and UTs contributions is the promotion of a dialogical multivocality (Liu, 2017). MTs and UTs seemed interested in promote the intervention of the different voices within the settings, and also the dialogue among them. For so doing, they used a particular sequence of conversation: first, they let the participants to freely contribute ('Encourager' role), and then they increase their own control on the conversation ('Initiator' role), through the combination of both nondirective (synthesising the participants' contributions, connecting different views) and directive (presenting their own representation of the situation, confronting the participants' views) strategies.

In spite of those similar actions, MTs and UTs still differed on the issue of the relationship between theory and practice. MTs underlined that their contributions aimed to a situated, contextual use of theory, that they consider realistic and adjusted to the actual situations. Meanwhile, UTs highlighted that their role was to promote the use of theory as a conceptual mediator for a more abstract and complex representation of the situations. Therefore, MTs took a role of situating or contextualising theory and showing how practice constraints and limits the use of theory, whereas UTs insisted in the need of abandon a narrative description of actions and situations.

The Joint setting, however, appears to have fostered dialogue between the different perspectives of MTs and UTs-school and university; a dialogue based on mutual respect and listening, and on an approach that sought to interpret, rather than judge, the actions and views of all those involved. The nature of the Joint setting was such that different perspectives could be expressed through a conversation that sought a symmetrical-rather than hierarchical-relationship between the various participants, and this seems to have been key in terms of creating productive synergies among the participants and enabling students to participate and reflect from a position of discursive equality. In this sense, it is interesting that all the participants attributed to the UTs a role related to promote equity and dialogue among all the voices in the Setting. 
In particular, UTs had the role, on the one hand, of not imposing their voice to the other, refusing to maintain the traditional hierarchy of the university in teacher training, and promoting a dialogue based on the mutual acknowledgement and valuation of all the involved voices. Solving tensions between the participants was also a part of this attributed role; so was searching for common ideas and criteria, known and possibly accepted by all the participants, which could be used as a common ground for progress. In this sense, the Joint setting can be considered as a 'third space' or 'hybrid space', that can facilitate the development of a new community of practice, and also affect the original-school and university-communities. This is consistent with other proposals on how this kind of dialogic interaction can help build communities of practice (Helgevold, 2016)

Moreover, the role of MTs and UTs along the settings, particularly the Joint setting, seems to constitute a form of peer mentoring, because of mutual engagement with the learning of all the participants. In this sense, it is relevant that both MTs and UTs claimed that participation in the settings helped them to be more conscious on their own role as teacher educators. First, because they were aware of the need of their active intervention in order to help the student teachers to construct knowledge on the situations of practice and on the relationship between theory and practice. Second, because they could identify some relevant difficulties of the student teachers in developing their professional knowledge, and they could explore how to support them, both individually and collaboratively. Finally, because they could experience the challenges involved when the education of student teachers is approached from mutual coresponsibility.

\section{Conclusions}

Our results point that the formative value of practicum within teacher training can be enhanced when MTs and UTs work together on an equal footing and with shared roles. The design and development of a set of Settings for dialogue and reflection articulated around the 'Joint setting' (a third, hybrid space based on dialogue and reflection) can contribute to create communities of expansive practice and a more synergistic relationship between school and university, and can improve the participants' learning in relevant ways.

Our results must be considered with due caution, because of the low number of participants and the somehow exploratory character of the study. However, we consider that they suggest some implications for practice that are worth considering: a global non-directive role of MTs and UTs, combined with the strategic use of both directive and non-directive forms of intervention; the need of a different but complementary role of MTs and UTs for the elicitation and construction of the student teachers' knowledge; the need of a theory/practice coordinated approach as a basis for reflection and interpretation of practical situations and teaching actions; and the need of progressively sharing a representation of teachers' knowledge and teachers' training.

In the process of creating an expansive community of practice, and concerning MTs, our results underline the need that MTs are attributed and can adopt a true formative role, helping the students to reflect on practice and to connect, in a situated, contextualised manner, theory and practice. Results also show that it is important for student teachers to experience the collective dimension of teaching, by participating in joint discussions and 
decision taking between their MTs and other colleagues at the school. Concerning UTs, it seems that they have a key role in order to construct an affective and emotional climate that allows collaboration with MTs, and in order to promote collaboration among teachers and among teacher students. It seems to be fundamental, to this extent, that UTs recognise the diversity of MTs and schools. It also seems fundamental that UTs support the process of constructing shared criteria for the analysis of practical situations. Finally, concerning collaboration itself, our results support the interest of: (i) creating different and complementary spaces of collaboration; (ii) adopting the analysis and reflection on authentic practical situations as the core task within those spaces; (iii) addressing those spaces from a nonhierarchical perspective, in which theory informs the analysis and understanding of practical situations but practice and practical knowledge are not subordinated to academic knowledge; and (iv) recognising and empowering the diverse and complementary contributions of MT and UT can make to the interaction with, and the education of, student teachers.

In the view of Reynolds, Ferguson-Patrick, and McCormack (2013): 'a key role of a teacher educator is to work the interface between the academic world, the world of teacher education and the world of the practising teachers' (p. 309). We believe that our proposed approach offers a shared platform on which this role can be fulfilled. At the same time, our study points to the interest and need of future studies, dealing with issues that have not been considered in enough detail in our work, and that should be addressed more deeply. Two of these issues are particularly worth mentioning. First, a more detailed analysis of interactions among the participants in the different spaces is needed. In particular, analysing the discursive strategies that could help to promote and consolidate collaboration among the participants in each space would be, in our view, of much interest. Second, it also would be of much interest to analyse how collaboration between MTs and UTs could evolve and develop over time, when they have the opportunity to establish a middle-term or long-term collaboration.

\section{Disclosure statement}

No potential conflict of interest was reported by the authors.

\section{Funding}

This work was supported by the "Agència de Gestió d'Ajuts Universitaris i de Recerca - Agency for Management of University and Research Grants" (AGAUR) under Grant 2014 ARMIF 00052.

\section{Notes on contributors}

Teresa Mauri (PhD in Psychology) is a teacher and Professor at the University of Barcelona. Her current research focuses on two major areas: first, the study of the formation and development of teachers' practical knowledge, based on the analysis of the collaborative reflection between teachers in professional contexts and between tutors and teacher students in the practicum period; second, evaluation and formative feedback in Higher Education. She coordinates the line of research named "Joint activity, knowledge and learning in professional communities" of the Interuniversity Doctoral Program on Educational Psychology (DIPE). 
Javier Onrubia (PhD in Psychology) is a Tenured Lecturer at the University of Barcelona. HIs research has focused on studying processes of educational assistance, from a sociocultural perspective. In recent years, he has studied these processes in three particular kinds of situations: student teachers' joint reflection on teaching practice, computer-supported collaborative learning and collaborative school consultation.

Rosa Colomina ( $\mathrm{PhD}$ in Psychology) is a Tenured Lecturer at the University of Barcelona. She has studied the mechanisms of educational assistance in adult-children interactional situations in family contexts and between teacher and students in formal teaching and learning situations. Currently, her research focuses on the study of reflection processes on practice situations for the improvement of teacher training.

Marc Clarà ( $\mathrm{PhD}$ in Psychology) is a Serra Hunter Fellow at the University of Lleida. His research interests include teachers' reflection, teachers' emotion and decision-making, and dialogic educational interaction, especially collective inquiry.

\section{References}

Anagnostopoulos, D., Smith, E. R., \& Basmadjian, K. G. (2007). Bridging the university-school divide horizontal expertise and the "two-worlds" pitfall. Journal of Teacher Education, 58, 138-152.

Braun, V., \& Clarke, V. (2006). Using thematic analysis in psychology. Qualitative Research in Psychology, 3, 77-101.

Ch., Y., \& He, C. (2010). Transforming the existint model of teaching practicum: A study of Chinese EFL Student teachers' perception. Journal of Educational for Teaching, 36, 57-73.

Cochran-Smith, M., \& Lytle, S. L. (2009). Inquiry as stance: Practitioner research in the next generation. New York, NY: Teachers College Press.

Cope, P., \& Stephen, C. (2001). A rol for practising teachers in initial teacher education. Teaching and Teacher Education, 17, 913-924.

Crasborn, F., Hennissen, P., Brouwer, N., Korthagen, F., \& Bergen, T. (2010). Capturing Mentor teachers' reflective moments during mentoring dialogues. Teachers and Teaching: Theory and Practice, 16, 7-29.

Crasborn, F., Hennissen, P., Brouwer, N., Korthagen, F., \& Bergen, T. (2011). Exploring a twodimensionals model of mentor teacher roles in mentoring dialogues. Teaching and Teacher Education, 27, 320-331.

Cuenca, A., Schmeichel, M., Butler, B. M., Dinkelman, T., \& Nichols, J. R., Jr. (2011). Creating a third space" in student teaching: Implications for the university supervisor's status as outsider. Teaching and Teacher Education, 27, 1068-1077.

Darling-Hammond, L., \& Lieberman, A. (2012). Teacher education around the world: Changing policies and practices. New York, NY: Routledge.

Edwards, A., \& Protheroe, L. (2004). Teaching by proxy: Understanding how mentors are positioned in partnership. Oxford Review of Education, 30, 183-193.

Erbilgin, E. (2014). Examining a program designed to improve supervisory knowledge and practices of cooperating teachers. Teaching Education, 25, 261-293.

Furlong, J., Barton, I., Miles, S., Whiting, C., \& Whitty, G. (2000). Teacher education in transition. Buckingham: Open University Press.

Geerarerts, K., Tynjälä, P., Markkanen, I., Pennanen, M., Heikkinen, H. L. T., \& Gijbels, D. (2015). Peer-group mentoring as a tool for teacher development. European Journal of Teacher Education, 38, 358-377.

Gorodetsky, M., \& Barak, J. (2008). The educational-cultural edge: A participative learning environament for co-emergence of personal and institutional growth. Teaching and Teacher Education, 24, 1907-1918.

Grossman, P., \& Loeb, S. (Eds.). (2008). Alternative routes to teaching. Mapping the new landscape of teacher education. Cambridge, MA: Harvard Education Press. 
Gutierrez, K., Rymes, B., \& Larson, J. (1995). Script, counterscript, and underlife in the classroom: James Brown versus Brown v. Board of education. Harvard Educational Review, 65, 445-471.

Harrison, J., Lawson, T., \& Wortley, A. (2005). Mentoring the beginning teacher: Developing profesional autonomy through critical reflection on practice. Reflective Practice, 6, 419-441.

Heikkinen, H. L. T., Jokinen, H., \& Tynjälä, P. (2012). Teacher education and development s lifelong and lifewide learning. In H. L. T. Heikkinen, H. Jokinen, \& P. Tynjälä (Eds.), Peergroup mentoring for teacher development (pp. 3-30). London: Routledge.

Helgevold, N. (2016). Teaching as creating space for participation-Establishing a learning community in diverse classrooms. Teachers and Teaching: Theory and Practice, 22, 315-328.

Hennissen, P., Crasborn, F., Brouwer, N., Korthagen, F., \& Bergen, T. (2008). Mapping mentor teachers' roles in mentoring dialogues. Educational Research Review, 3, 168-186.

Hennissen, P., Crasborn, F., Brouwer, N., Korthagen, F., \& Bergen, T. (2011). Clarifying pre-service teacher perceptions of mentor teachers developing use of mentoring skills. Teaching and Teacher Education, 27, 1049-1058.

Hoffman, J. V., Wtzel, M. M., Maloch, B., Greeter, E., Taylor, L., Dejulio, S., \& Vlach, S. K. (2015). What can we learn from studying the coaching interactions between cooperating teachers and preservice teachers? A literature review. Teaching and Teacher Education, 52, 99-112.

Korhonen, H., Heikkinen, H. L. T., Kiviniemi, U., \& Tynjälä, P. (2017). Student teachers' experiences of participating in mixed peer mentoring groups of in-service and pre-service teachers in Finland. Teaching and Teacher Education, 61, 153-163.

Le Cornu, R. (2005). Peer mentoring: Engaging pre-service teachers in mentoring one another. Mentoring \& Tutoring: Partnership in Learning, 13, 355-366.

Levine, T. H. (2010). Tools for study and design of collaborative teacher learning: The affordances of diferent conceptions of teacher community and activity theory. Teacher Education Quaterly, Winter, 109-130. Retrieved from http://www.jstor.org/stable/23479301

Liu, K. (2017). Creating a dialogic space for prospective teacher critical reflection and transformative learning. Reflective Practice, 18, 805-820.

Lynch, D., \& Smith, R. (2012). Teacher education partnerships: An Australian research-based perspective. Australian Journal of Teacher Education, 37, 132-145. Retrived from http://ro.ecu. edu.au/ajte/vol37/iss11/

Maandag, D. W., Deinum, J. F., Hofman, A. W. H., \& Buitink, J. (2007). Teacher education in schools: An international comparison. European Journal of Teacher Education, 30, 151-173.

Mena, J., García, M., Clarke, A., \& Barkatsas, A. (2016). An analysis of three different approaches to student teacher mentoring and their impact on knowledge generation in practicum settings. European Journal of Teacher Education, 39, 53-76.

Mena, J., Hennisen, P., \& Loughran, J. (2017). Developing pre-service teachers'professional knowledge of teaching: The influence of mentoring. Teaching and Teacher Education, 66, 47-59.

Moran, A., Abbott, L., \& Clarke, L. (2009). Re-conceptualizing partnerships across the teacher education continuum. Teaching and Teacher Education, 25, 951-958.

Mtika, P., Robson, D., \& Fitzpatrick, R. (2014). Joint observation of student teaching and related tripartite dialogue during field experience: Partner perspectives. Teaching and Teacher Education, 39, 66-76.

Mullen, C. A. (2000). Constructing co-mentoring partnership: Walkways we must travel. Theory into Practice, 39, 4-11.

Reynolds, R. K., Ferguson-Patrick, K., \& McCormack, A. (2013). Dancing in the ditches: Reflecting on the capacity of a university/school partnership to clarify the role of a teacher educator. European Journal of Teacher Education 36, 36, 307-319.

Smith, I., Brisard, E., \& Menter, I. (2006). Models of partnership development in initial teacher education in the four components of the United Kingdom: Recent trends and corrent challenges. Journal of Education for Teaching, 32, 147-164.

Van Manen, M. (2003). Writing in the dark. phenomenological studies in interpretative inquiry. California: Left Coast Press, INC.

Zeichner, K. (2010). Rethinking the connections between campus courses and field experiences in college- and university-based teacher education. Journal of Teacher Education, 61, 89-99. 